DEPÓSITO LEGAL ZU2020000153

Esta publicación científica en formato digital

es continuidad de la revista impresa

ISSN 0041-8811

E-ISSN 2665-0428

Revista

de la

Universidad

del Tunlia

Fundada en 1947

por el Dr. Jesús Emrique Lossada

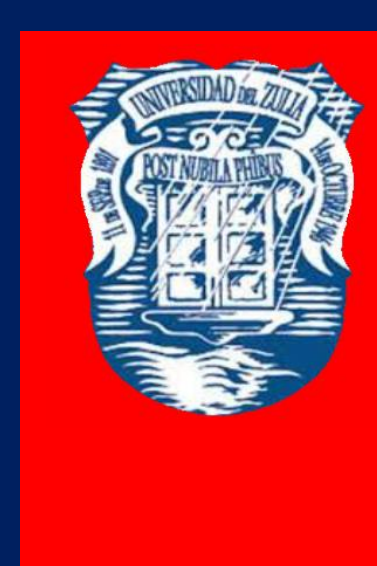

Ciencias

Sociales

y Arte

Aกัต 11 No 31

Septiembre - Diciembre 2021

Tercera ípoca

Maracailbo-Venezuela 


\section{Campoma, una huella de ancestralidad cultural africana}

\section{Orlando Enrique Balbás S.*}

RESUMEN

En el siglo XVI, Campoma, un pequeño poblado de Venezuela, fue un cumbe. Los negros esclavizados huían de las haciendas con la idea de concretar su libertad a través de las comunidades de cimarrones, que constituían los cumbes. El objetivo central de este artículo es presentar los hallazgos preliminares de un trabajo de campo, compartido con reconocidos personajes de Campoma, quienes al margen de toda la influencia de culturas foráneas, mantienen muchas creencias, tradiciones y costumbres heredadas de África. Dicho legado se conserva por los testimonios que se han trasmitido por varias generaciones, y es fuente que nutre la memoria colectiva de los lugareños. Actualmente, las influencias mediáticas y la desaparición de las fronteras culturales por la tecnología cibernética, tiende a fundir las culturas locales. Sin embargo, Campoma sigue siendo un testimonio vivo de la presencia de África en Venezuela y su influencia en nuestra cultura.

PALABRAS CLAVE: Cultura africana, ancestralidad, memoria colectiva, costumbres, identidad cultural venezolana.

*Universidad Latinoamericana y del Caribe, Cumaná - Estado Sucre, Venezuela, Orlandobalbas27@gmail.com

Recibido: 11/03/2020

Aceptado: 21/05/2020 


\section{Campoma, a footprint of african culture ancestrality}

ABSTRACT

In the 16th century, Campoma, a small town in Venezuela, was a cumbe. The eslaved blacks fled the estates with the idea of realizing their freedom through the communities of marooms, which constituted the cumbes. The main objective of this article is to present the preliminary findings of a field work, shared with renowned Campoma characters, who, apart from all the influence of cultures foreign, maintain many beliefs, traditions and customs inherited from Africa. These beliefs, traditions and customs are maintained by the testimonies that for years have been transmitted for several generations and are sources that nourish the collective memory of the locals. Currently, media influences and the sudden disappearance of cultural and territorial borders by cyber technology tend to merge local cultures, however, Campoma preserves the essence of its cultural physiognomy, with its inevitable changes, but it remains a living testimony of the presence of Africa in Venezuela and its influence on our culture.

KEYWORDS: African Culture, ancestrality, collective memory, customs, Venezuelan cultural identity.

Introducción

Algunos pueblos en el estado Sucre, fundamentalmente los ubicados en la Península de Paria, al noreste de Venezuela, son testimonio vivo de la presencia y herencia de la cultura africana. Zonas como las de Campoma, Irapa, Cariaco, Guiria, y Yaguaraparo, constituyen centros poblacionales testigos de ese imborrable proceso histórico. El contacto con su gente, con sus vivencias y sus modos de vida, todas, revestidas del inocultable atavismo africano que los abarca, nos devela testimonios signados por historias fantásticas que exaltan el espíritu libertario de sus primeros moradores en tiempos de la colonia. La esencia identitaria aun aflora en sus discursos y en sus acciones cotidianas, los cuales reflejan su indeleble huella ancestral.

El objetivo central de este artículo es presentar los hallazgos preliminares de una experiencia de aprendizaje compartida con reconocidos personajes de la localidad de Campoma, quienes al margen de toda la influencia de culturas foráneas, como consecuencia del proceso de globalización, mantienen muchas creencias, tradiciones y costumbres heredadas de África. 
Dichos hallazgos, también se nutren de algunos aportes del extinto antropólogo Adonis Romero, quien fue incansable estudioso de las comunidades asentadas esa zona. Romero efectuó labores de reconocimiento de materiales hispánicos, prehispánicos y contemporáneos, preservando la historia de los poblados de Campoma y sus adyacencias.

Sin duda, fue muy valioso, el apoyo directo y preciso de sus actores, la gente de Campoma, quienes nos brindaron, a través de sus subjetividades, su conocimiento detallado y testimonial de las vivencias de ese poblado. Participaron la cultora Berta Cova, originaria de Campoma y fiel representante de la cultura africana. Ella es descendiente de esclavos traídos del Congo; y Tirso Cova: oriundo de Cariaco, fiel exponente y defensor de la herencia bantú. Él tiene importantes investigaciones en ese campo y es habitante de Campoma.

Uno de los aspectos más significativos, es que Campoma fue refugio de los africanos esclavizados que se rebelaron ante la opresión y maltrato de los amos de las haciendas. Campoma era un cumbe, un territorio habitado por rebeldes esclavos que intentaban recuperar su dignidad humana. Paralelamente, debemos reconocer que la asunción del tema conduce indefectiblemente a plantearnos la trascendencia del mestizaje en la sociedad venezolana, como eje donde confluye todo el entramado cultural de lo que hoy nos identifica como pueblo. Claro está, hay especificidades en toda la vasta geografía de nuestros territorios americanos, constituidos en naciones. Pero, Venezuela es una representación muy importante en ese proceso de interculturalidad, y Campoma es una referencia que no se debe invisibilizar.

El trabajo está estructurado en cinco partes: en la primera: Africanidad, algunos dilemas coyunturales, se describen las confrontaciones surgidas en el seno de algunas organizaciones a favor o en contra de la adopción del término africanidad. En la segunda, los cumbes, espacios de rebeldía, se expone algunas ideas sobre los cumbes, y las motivaciones que condujeron a su establecimiento. Con el paso de los años, esos asentamientos, que representaban el espíritu libertario del esclavo, se transformaron en los pueblos de hoy, marginados social y económicamente. La tercera parte del artículo, Esclavos en la independencia, da parte de los movimientos que propulsaron la idea de legislar los asuntos relacionados con los esclavos. La cuarta parte, En el estado Sucre, África vive, se destaca como hecho histórico, las primeras negociaciones vinculadas con la trata de negros que se iniciaron en el Estado Sucre y que abrió 
las puertas a todo este proceso de interculturalidad que nos ha acompañado desde entonces. En el desarrollo de la parte cinco, se describen los significados de los saberes compartidos con algunos de los pobladores más emblemáticos de Campoma, y su decidido empeño por preservar los valores identitarios de ese histórico pueblo sucrense. Finalmente, se formulan algunas conclusiones.

\section{1.-Africanidad, algunos dilemas coyunturales}

En la revista digital Africanidad (2017), se define este constructo como "la cualidad socio-cultural y político reivindicativa de ser africanos, un sentimiento de pertenencia y vinculación compartido entre África y la diáspora africana en el mundo". Nos interesa iniciar este apartado del artículo con esta definición para exaltar los movimientos que alrededor del planeta, trabajan incesantemente por rescatar y fortalecer los valores identitarios de los pueblos de África, en un contexto que aún impone abismales desigualdades sociales hacia la población negra en muchas partes del mundo. Y Venezuela, no es la excepción. A lo largo y ancho de su geografía, se percibe el abandono de las zonas mayormente poblada por negros. La desatención también ha alcanzado a los pueblos de Sucre, históricamente.

Al parecer, no han sido suficientes tantos siglos de maltrato hacia los africanos y sus descendientes. Cuesta creer, que aun en nuestro tiempo, haya tantos desencuentros. En nuestro país, han surgido voces que repudian el término "africanización", condenan el hecho de que la esclavitud fue aupada por los propios africanos, como para favorecer intentos que promuevan la adopción de la cultura afrodescendiente, que de acuerdo a su interpretación adolece de identidad, de historia, de una lengua, de costumbres y de valores, y que solo responde a intereses dominantes (Palacios y Guevara, 2011). Son los defensores del término cultura negra. Por otro lado, hay sectores convencidos de que los valores identitarios africanos no están definidos, y antes de emprender cualquier proyecto vinculado a la africanización, se hace impostergable dotar de contenido la idea de africanidad, establecer las bases de unos valores que los fundamenten y les otorguen significado al ser africano, pero de manera auténtica. Contrasta con esto, los fundamentos de los propulsores de la africanidad, quienes han edificado una singular 
estrategia para promover y exaltar los valores africanos como legado de su cultura ancestral en nuestro país.

La intención es plasmar en este artículo la existencia de una simbología y las manifestaciones que le dan sentido a una cultura transversalizada por las características heredadas desde los esclavos que fueron traídos desde áfrica. Lo dialógico debe persistir, la simbología pervive en algunos espacios geográficos de Venezuela como testimonio de la realidad colonial. La esclavitud y el surgimiento de poblaciones y comunidades a raíz de la creación de los cumbes en varias partes del país, fundamentalmente donde hubo haciendas de cacao, café y caña de azúcar, así lo confirman.

Los descalificativos y visión histórica prejuiciada, crearon desde los que escriben una idea mítica y fuera de lugar, una madeja de leyendas acerca de estos hombres y mujeres obligados a dejar sus lugares de origen para ser traídos a territorios desconocidos, tal y como expresa Acosta Saignes (1986a: 148):"La ignorancia de la historia africana ha conducido a esquemas injustos y generalizaciones, cuyas raíces están en la época de la esclavitud: que los africanos que llegaron a América, eran bárbaros, ignorantes, feroces, primitivos...”

\subsection{Los cumbes, espacios de rebeldía}

Las manifestaciones concretas de la cultura africana en Venezuela, sobreviven en espacios específicos donde se logra cohesión mediante la simbología. Allí, en los intrincados lugares elegidos por los esclavos cimarrones, para establecer los cumbes, luego de escapar de sus amos. Luego de trabajar en las grandes haciendas de cacao y café, se consolidaron esos espacios de cimarronaje, en pueblos y comunidades que existen en la actualidad. Es el caso de Ocoita, Barlovento en el estado Miranda y Campoma del estado Sucre. En medio de las turbulencias políticas y las proclamas antiesclavistas, se mantuvieron lazos de unión, relaciones entre blancos, indios y negros, producto de la identificación cultural. Piñerúa (2018), se refiere a los cumbes que se establecieron en Venezuela durante el siglo XVI, de la manera siguiente:

En Venezuela, los pueblos de fugitivos africanos se conocieron como cumbes o rochelas, lo que en Brasil se conoció como quilombos o mocambos y en Colombia palenques. Los esclavos negros prófugos formaban comunidades estables, basándose en elementos culturales traídos de África, unidos a 
elementos culturales españoles, productos de la convivencia en su esclavitud, como de elementos culturales indígenas, que se les unían al desertar de las misiones. Los cumbes fueron también lugares de refugio para soldados desertores blancos y pardos de las Antillas

Las exigentes y terribles condiciones del trabajo esclavo hicieron difícil o casi imposible, su inserción en la vida cultural de la sociedad venezolana. En la sociedad colonial, se tenía la certeza de que el esclavo que dinamizaba productivamente la economía de la hacienda, carecía de capacidad para pensar y hasta de sentir. La condición de esclavos, en la sociedad colonial, tenía diversas connotaciones. Para algunos, no era un ser humano, sino una mercancía para el trabajo; para otros, no era un ser sensible, no tenía sentimientos, ni sentían dolor en sus cuerpos; tal vez eso explique, de algún modo, la bestialidad de las torturas que recibían. En concreto, era un ser desplazado de la sociedad, sin derechos humanos, políticos, ni religiosos.

Acosta Saignes (1986b:22) postuló en uno de sus magníficos escritos en torno a esta realidad lo siguiente: "Rige, sin duda, entre muchos, la creencia de que los esclavos no pensaban, no poseían concepciones del mundo, de la sociedad donde vivían, de la injusticia, social. Priva la concepción de que carecían de concepciones políticas".

Sin embargo, los esclavos dieron innumerables manifestaciones de su inteligencia, de su espíritu de lucha por recuperar su dignidad y alcanzar su libertad. A lo largo y ancho de Suramérica mostraron su resistencia contra el oprobio español y los blancos dueños de las haciendas, de diversas maneras: insurrecciones, bajo rendimiento en el trabajo, incendios, asesinato de capataces, fueron algunas de las estrategias que usaron para rebelarse. Precisamente una de las formas de resistencias fue escapar de la opresión del amo y establecerse en los cumbes, donde exhibieron su capacidad para organizase.

No obstante, vale la pena destacar que uno de los obstáculos que han enfrentado antropólogos e historiadores, ha sido la reconstrucción del pasado histórico de los esclavos, a partir de la subjetividad de sus propias vivencias. Rojas (1993) refuerza la precedente afirmación y establece como razón el hecho de que no hay testimonios escritos de sus vidas, ni de sus luchas en esa época. Acosta Saignes, citado por Rojas, refiere en una de sus excelsas obras, que los estudios etnográficos en esa área se registran con base en los aportes de los descendientes de los esclavos. 
REVISTA DE LA UNIVERSIDAD DEL ZULIA. 3e época. Año ll N³1, 2020 Orlando Enrique Balbás S. /// Campoma, una huella de ancestralidad cultural africana, 223-236 DOI: http://dx.doi.org/10.46925//rdluz.31.15

Precisamente, los testimonios revelados por los descendientes de los esclavos que fundaron los cumbes en Campoma, son los que han enriquecido con sus relatos esta experiencia. Es de importancia vital, para mantener conexión con nuestras raíces identitarias, dar a conocer los aportes de la cultura africana en la venezolanidad. Es necesario insistir en que el mestizaje está allí, en cada rincón de la geografía nacional. Y el hecho de que las características indígenas, africanas o europeas predominen en algún grupo social, está relacionado con un mismo proceso y etapas de la dinámica social e histórica. Los fenómenos de la humanidad no están aislados y menos en el espacio territorial que es Venezuela.

\subsection{Los esclavos en la independencia}

La legislación que surgió en todo el proceso de lucha de la gesta emancipadora en Venezuela estuvo signada por las grandes contradicciones en la concepción de nuevas estructuras y relaciones de poder. Y dentro de ello, la justicia social como elemento fundamental para pregonar la libertad y la soberanía en nuestras tierras y el fin de la esclavitud. La época colonial mantenía un cerrado sistema social de castas y ello se reflejó en las debilidades políticas y sociales de los líderes de independencia para asumir posiciones que favorecieran la libertad de los esclavos y otorgarle derechos ciudadanos y humanos. Vale decir, que, casi la totalidad de los blancos criollos, propiciadores de la guerra contra España, eran también hijos de esclavistas o eran dueños de esclavos y por ello, las constituciones desde 1811 nunca abolieron el sistema económico basado en la esclavitud.

Esta legislación tuvo muy en cuenta el problema de la esclavitud, pero esta condición de la estructura económica y social de Venezuela se mantuvo a lo largo del siglo XIX. Villamizar (2012:48), sostiene al respecto:

La constitución de 1811 obvió el problema de la esclavitud; la de 1821 prohibía la trata de esclavos y aprobó la ley de manumisión, pero dejó pendiente la abolición de la esclavitud. La constitución de 1830 mantuvo la legislación que al respecto tenía la constitución de la República de Colombia y además amplió el derecho de los amos. Las posteriores legislaciones, tendieron a desmejorar las condiciones de los esclavos, hasta que el 24 de marzo de 1854, bajo el gobierno de José Gregorio Monagas, se promulga finalmente la ley de abolición. 
REVISTA DE LA UNIVERSIDAD DEL ZULIA. 3e época. Año ll N³1, 2020 Orlando Enrique Balbás S. /// Campoma, una huella de ancestralidad cultural africana, 223-236

DOI: http://dx.doi.org/10.46925//rdluz.31.15

Una profunda e imprevista guerra social arropó el sentido de la guerra de independencia. La crisis social aupada por las luchas de los esclavos contra los amos, los violentos enfrentamientos étnicos impulsados por los negros contra los blancos, animaron a los blancos criollos, entre ellos el Libertador, a abolir la mano de obra esclava.

Simón Bolívar, el Libertador, se constituyó en uno de los ideólogos antiesclavistas de la época independentista, en medio de una oligarquía conservadora y retardataria, partidaria de la economía esclavista, que luchaba por mantener la esclavitud. Esos blancos criollos y mantuanos se colocaron al lado de la monarquía.

En ese panorama real de la política, se destacaron ambivalencias y radicalismos. Bolívar se propuso eliminar y desaparecer de la faz de la tierra venezolana el flagelo de la esclavitud. Según Mijares (1978:18) “...Bolívar desembarcó en Carúpano, la población y sus fuertes fueron tomados a viva fuerza. De acuerdo con una promesa hecha a Petión, decretó inmediatamente la libertad de los esclavos...”

Simón Bolívar tenía un proyecto político para Venezuela y la América Meridional, en armonía con la justicia, la igualdad, la fraternidad y la libertad, inspirado en las ideas de la Revolución Francesa. Por esa razón, la estructuración de una nueva relación de poder en el continente, demandaba la eliminación del flagelo de la esclavitud, herencia del colonialismo.

Séame permitido llamar la atención del Congreso sobre una materia que puede ser de una importancia vital. Tengamos presente que nuestro pueblo no es europeo, ni americano del norte; que más bien es un compuesto de África y de América, que una emanación de la Europa; que hasta la España misma, deja de ser Europa por su sangre africana, por sus instituciones, por su carácter. Es imposible asignar con propiedad, a qué familia humana pertenecemos. La mayor parte del indígena se ha aniquilado, el europeo se ha mezclado con el americano y con el africano, y este se ha mezclado con el indio y el europeo. Nacidos todos del seno de una misma madre, nuestros padres diferentes en origen de sangre, son extranjeros, y todos difieren visiblemente en la epidermis: esta desemejanza trae un reto de la mayor trascendencia. (Bolívar, Simón. Discurso de Angostura, 15 de febrero de 1819) Escritos del Libertador. Sociedad Bolivariana de Venezuela. 1982. Tomo XV p-15.

La inspiración fundamental de los esclavos por su libertad, y todas las rebeliones desatadas para sus luchas, estaban sustentadas por las necesidades de revivir sus naturales formas de vida en el África y también en sus convicciones sobre la igualdad de todos los hombres 
ante Dios. Y esa búsqueda, se afianzaba ante la explotación y maltrato que recibían en las haciendas, y los llevaba con determinación a levantarse contra sus amos esclavistas.

Un relato expresado por el cronista Fray Pedro Simón, destacando la figura del esclavo Miguel, valida esa afirmación:

Prevenido de todo esto y dejando orden en la defensa del pueblo, que ya estaba acabado, y cómo se había de gobernar en su ausencia, sacó de él su gente Miguel. Y, en un llano, fuera de la empalizada con que lo dejaban cercado, les hizo una plática, diciendo: que la razón que les había movido a retirarse de los españoles, ya sabían, había sido por conseguir su libertad, que tan justamente la podían procurar, pues habiéndolos Dios criado libres como las demás gentes del mundo. (citado por: Acosta S., 1986b: p.22).

No obstante, es imperativo referir, que durante la guerra de independencia, como consecuencia de la crisis económica y social, el régimen de esclavitud, tuvo un desgaste significativo. Muchos esclavos participaron en las acciones armadas, algunos como realistas, otros, como patriotas, y esto contribuyó a fortalecer los planes de fugas de los esclavos. Durante este periodo, la efectividad productiva del esclavo también se debilito sustancialmente. Y esta reducción condujo a la sustitución de la esclavitud por la modalidad de servidumbre.

Estas condiciones, en opinión de Brito F. (1967), probablemente alentaron a los terratenientes a considerar la necesidad de abolir legalmente la esclavitud porque las luchas que sostenían los esclavos por su libertad se profundizaban cada vez más. Entre 1821 y 1854, se registraron aproximadamente 150 rebeliones promovidas por esclavos, fugas individuales, revueltas, conspiraciones que mantuvieron en constante tensión el ambiente social y político en el territorio.

Las luchas por la libertad estaban plenamente justificadas. Solo basta con detenernos a pensar que la cultura africana fue trasladada al "Nuevo Mundo", a nuestra América, forzosamente, con el compulsivo y violento desterramiento de colectividades completas, reyes, reinas, príncipes, sabios, jóvenes, niños, viejos, provocando el más terrible proceso de desarraigo de civilizaciones. 
REVISTA DE LA UNIVERSIDAD DEL ZULIA. 3ª época. Año 11 N³ 31, 2020 Orlando Enrique Balbás S. /// Campoma, una huella de ancestralidad cultural africana, 223-236

DOI: http://dx.doi.org/10.46925//rdluz.31.15

\section{El estado Sucre, pionero en trata de negros}

El estado Sucre, por ser un lugar ubicado en la región nororiental de Venezuela, a orillas del Mar Caribe, fue el primer lugar del Continente americano donde se puso en práctica el comercio o trata de negros. Humboldt menciona a Cumaná, describe el proceso de subastas de los primeros 500 esclavos africanos, seres humanos pertenecientes a unas culturas distintas a las nuestras, con organizaciones y estructuras socio-políticas sujetas a la cosmovisión y necesidades en su propia realidad.

La investigación sobre elementos africanos en algunas poblaciones del Estado Sucre, tiene escasos antecedentes. Esto representa un breve esbozo de los resultados del trabajo de campo, aun inconcluso, realizado durante varios días, en Campoma. Se trata de un estudio más ambicioso, cuya intención es fortalecer el proceso de búsqueda de los saberes ancestrales en cada rincón del oriente del país. El estudio se enmarca en el contexto del área cultural.

La cultura es un tema de complejidad insospechada, de tal variedad, diversidad y visiones que sobrepasan la capacidad de tiempo para dilucidar el fenómeno. Al respecto Monsalve (2011: 5), señala:

No hay dudas sobre la influencia que desde siempre ha tenido en Venezuela el contexto político a la hora de establecer la orientación que va a dar al mundo de la cultura, bien para desarrollarla o inhibirla. Tema hasta ahora nunca bien resuelto, entre las concepciones que manejan. Estos dos tipos de actores, los de la cultura y quienes la miran desde la opción política y también aquellos que se tienen como los actores que se constituyen en sus usuarios o depositarios. Obvio, imposible comprender las políticas culturales, desligándolas de las representaciones o símbolos, que los tres actores atribuyen a la cultura y la política en un momento determinado.

Se trata del reconocimiento de la interculturalidad y dentro de esto el proceso de transculturación desarrollado en la guerra de conquista y colonización de España en América. Quiere decir que analizar la cultura venezolana sin tomar en cuento las tres civilizaciones involucradas, es dejar incompleto un proceso histórico de aleación cultural definitoria de la venezolanidad. 
REVISTA DE LA UNIVERSIDAD DEL ZULIA. 3e época. Año ll N³1, 2020 Orlando Enrique Balbás S. /// Campoma, una huella de ancestralidad cultural africana, 223-236

DOI: http://dx.doi.org/10.46925//rdluz.31.15

\section{Campoma, testimonio de la ancestralidad africana}

La zona de Campoma, en el estado Sucre, es producto de un Cumbe. Campoma no aparece registrada en la mayoría del material histórico bibliográfico disponible, como originada de un Cumbe en la historia de la esclavitud en Venezuela. Los pueblos generalmente referidos son los de Occidente: Maracaibo, Trujillo, Barcelona (Nueva Andalucía), Caracas, Aragua, Miranda, Barlovento.

Los Cumbes fueron centros de resguardo de los esclavos fugados. Campoma es un testimonio vivo de esa comunidad rebelde antiesclavista. Hoy por hoy, su gente, de raíces profundamente afro, conserva intactas muchas de sus increíbles tradiciones. Sus leyendas se mantienen en la memoria colectiva de sus pobladores. Candau (2014) señala con respecto a la memoria colectiva que los mitos, las leyendas, las creencias, las diferentes religiones son construcciones de la memoria colectiva. Así, los miembros de una sociedad dada buscan traspasar una imagen de su pasado de acuerdo con su propia representación de lo que son, algo totalmente explícito en el mito de los orígenes. De modo que persiste un claro interés en mantener vivo el pasado para preservar el valor de su identidad cultural, de profundas raíces africanas.

En Campoma, los saberes del pasado colonial sucrense se comparten con prodigalidad y con un propósito bien definido: mantener el legado ancestral africano. Un legado que se manifiesta en las narraciones de los líderes más representativos del área. Testimonios que se reproducen para promover los valores de identidad en las nuevas generaciones, también y para el conocimiento de quienes muestran interés en ese pueblo lleno de historias. Un pueblo que ha construido, a partir del legado africano, su modo de vida, sus vivencias cotidianas, sus maneras de interactuar con el mundo.

El censo de hábitat y vivienda del 2011, demuestra que los habitantes de Campoma se reconocen como afro descendientes, y consideran que pueden aportar a Venezuela su cultura. Los campomeros muestran orgullo por su cabello "afro" y mantienen una constante dinámica en sus costumbres, que han podido ser debilitadas por la interconexión globalizante, pero no desarraigadas. Hay exponentes de la tradición en Campoma que testimonian la herencia cultural africana, entre ellos, Berta Cova, quien es representante afrodescendiente del estado Sucre en el 
mundo. Ella, fiel exponente de la cultura afro, extiende a través de la oralidad los saberes de sus ancestros. Promueve la difusión de los peinados de clinejas con dibujos hechos de los propios cabellos y habla de lo afrodescendiente con absoluto dominio. Conoce la medicina afro-indígena y prescribe, y sana enfermedades a través de sus conocimientos botánicos ancestrales. No conforme con eso, expone su talento artístico a través de la música y los bailes tradicionales de la región.

Berta Vargas, hoy desaparecida, nacida en Cerezal pero reconocida en Campoma como defensora de la negritud. Sus muñecas negritas de trapo, representan una simbología que identifica los pueblos de Sucre. Perucho Cova, máximo ejecutor de la cuereta y el joropo estribillo, Guillermina Ramírez de Cariaco, recreó sus bailes y cantos en el mito de la culebra de la Laguna de Campoma, una leyenda que tiene su base en el amor. Fue una cultora, mujer de pueblo que mantuvo en sitial de reconocimiento permanente las tradiciones culturales de la región. Creó el grupo “Las Taparitas”. El pueblo de Campoma, de antepasado africano, centra su actividad económica en la artesanía, la pesca y la agricultura.

Es de esa agricultura y su sistema de plantaciones en las haciendas de cacao, café y caña de azúcar, de donde comienzan a manifestarse los descontentos de los esclavos y las fugas de los cimarrones. Dando origen, progresivamente, a los cumbes, que como Campoma, fueron desarrollándose y convirtiéndose en pueblos importantes del estado Sucre.

\section{Conclusiones}

La invisibilización de los aportes de los negros o afrodescendientes ha impedido su reconocimiento como parte fundamental de la identidad nacional. A la luz de la reconstrucción de su pasado, de sus vivencias e historicidad, los pueblos van tejiendo el entramado de su identidad. Sin embargo, el pasado de los pueblos latinoamericanos se fue construyendo con base en la discriminación y exclusión del patrimonio cultural de los indígenas y afrodescendientes. Venezuela no ha sido la excepción. No podemos desestimar el olvido al cual han sido sometidas las poblaciones que sirvieron de asiento a los cumbes durante la época de la esclavitud. Un olvido que no solo se traduce en la marginalización de sus necesidades socios económicas, sino que también toca la falta de reconocimiento de sus aportes a nuestra identidad. Campoma posee 
historia significativa. Su pasado como zona de libertad en la época de la esclavitud, lo dignifican. Sin embargo, es una historia recurrentemente olvidada. Por fortuna, los campomeros, se han empeñado en apelar a su anclaje memorístico y a su simbología, para traer al presente las vicisitudes de sus antepasados ancestrales. Le conceden vida y perpetuidad a una historia de rebeldía y de luchas, en el contexto de una de los más atroces acontecimientos que marcaron la vida de los hombres y mujeres de África, y que aún, en pleno siglo XXI, se manifiesta de diversas maneras.

Actualmente las influencias mediáticas y el modernismo urbano, unido a la desaparición súbita de las fronteras culturales y territoriales por la tecnología cibernética, permiten ir fundiendo las culturas locales e imponiendo las grandes tendencias de las ciudades.

Sin embargo, Campoma en el estado Sucre mantiene su fisionomía cultural esencial, con sus cambios inevitables, pero sigue siendo un testimonio vivo de la presencia de África en Venezuela y su influencia en nuestra cultura.

\section{Referencias}

Acosta Saignes, M. (1986a) Procedencia de los africanos. Colección conocer a Venezuela. Historia, Tomo II. Madrid: Editorial Salvat.

Acosta Saignes, M. (1986b). Las Ideas de los Esclavos Negros en América. Caracas: Talleres Gráficos del Congreso de la República.

Africanidad (2017) [Documento en Línea]. Disponible en: http://www.africanidad.com/2017/01/que-es-la-africanidad.html [Consulta: 2019, julio 21].

Brito Figueroa, F (1967). La población y la estructura social de Venezuela en las primeras décadas del siglo XIX. En Bulletin Hispanique. Tomo 69, Nro 3. Pp347 364

Candau, J. (2011). Memoria e Identidad. Buenos Aires: Ediciones del Sol.

Mijares, A. (1978). El libertador. Tomo II. Editorial Mexicana 1978. México DF.

Monsalve, T. (2011): La política cultural y el imaginario político. Revista Cultural de Venezuela: A plena Voz. (66) Caracas. Fundación Editorial El Perro y la Rana. 4-7.

Palacios, B. y Guevara, A. (2011). La Cultura negra trasciende la africanidad. Revista Digital América Latina en Movimiento. [Documento en Línea].Disponible: https://www.alainet.org > active [Consulta: 2019, agosto 27]. 
REVISTA DE LA UNIVERSIDAD DEL ZULIA. 3a época. Año $11 \mathrm{~N}^{\circ}$ 31, 2020 Orlando Enrique Balbás S. /// Campoma, una huella de ancestralidad cultural africana, 223-236

DOI: http://dx.doi.org/10.46925//rdluz.31.15

Piñerúa, F. (2018). Cumbes y Rochelas. Blog Antropología y Ecología UPEL [Documento en línea] Disponible: http://antropologiayecologiaupel.blogspot.com /2018/07/historia-deVenezuela-cumbe. [Consulta: 2019, mayo 30].

Rojas, R. (1993). La rebelión de los esclavos negros en Venezuela antes y después de 1798. Estudios de historia Social y económica de América, Revistas de la UAH Nro. 10 [Documento en línea]. Disponible: https://ebuah.uah.es/dspace/handle/10017/391 [Consulta: 2019, julio 15].

Villamizar, H. (2012). La atención médica a los presos enfermos siglo XVIII. En Revista "Desafío de la Historia" $N^{\circ} 34$. Caracas - Venezuela. 